\title{
Field Study of Inactivated Equine Rotavirus Vaccine
}

\author{
Hiroshi IMAGAWA ${ }^{1 *}$, Tetsuo KATO ${ }^{2}$, Hiroshi TSUNEMITSU ${ }^{3}$, Hidetoshi TANAKA ${ }^{4}$, \\ Shinsuke SATO $^{5}$ and Tohru HIGUCHI ${ }^{6}$
}

${ }^{1}$ Epizootic Research Center, Equine Research Institute, Japan Racing Association, 1400-4 Shiba, Kokubunjimachi, Shimotsuga-gun, Tochigi 329-0412, ${ }^{2}$ Nippon Institute for Biological Science, 9-2221-1, Shin-machi, Ome, Tokyo 198-0024, ${ }^{3}$ Shichinohe Research Unit, National Institute of Animal Health, Uminai-31, Shichinohe, Aomori 039-2586, ${ }^{4}$ Mejiro Stud, 308 Naruka, Toya-mura, Abuta-gun, Hokkaido 049-5832, ${ }^{5}$ Central Branch of Domestic Animal Clinic, Hidaka Agriculture Mutual Aid Association, 8-71 Hokusei-machi, Niikappu-cho, Niikappu-gun, Hokkaido 059-2403, ${ }^{6}$ Mitsuishi Animal Clinic Center, Hidaka Agriculture Mutual Aid Association, 200 Higashi-Horai, Mitsuishi-cho, Mituishi-gun, Hokkaido 059-3105, Japan

We aimed to determine the safety, immunogenicity and efficiency of an inactivated equine rotavirus vaccine. The vaccine was prepared with $G 3$ serotype equine rotavirus. A dose of 2 $\mathrm{ml}$ was inoculated twice with a 1-month interval into the cervical muscles of 60 pregnant mares (40 on farm $T$ and 20 on farm M). The first vaccination was conducted 2 or 3 months before full term. No abnormal signs were observed in the whole body or the inoculated area in any of the mares vaccinated. Serum neutralization antibody rose in $56(93.3 \%)$ of the 60 vaccinated mares. The 60 foals born to the vaccinated mares possessed neutralization antibody titers of 1:320 to 1:10240. Sixteen foals on farm T developed diarrhea caused by serotype $G 14$ rotavirus infection, but no foals on farm $M$ developed diarrhea. Diarrhea in the foals born to vaccinated mares was a slight illness in comparison with that in foals born to unvaccinated mares. The vaccine is safe and immunogenic for pregnant mares, and vaccineinduced maternal antibody in the foals can reduce the signs of diarrhea caused by rotavirus infection.

Key words: diarrhea, equine, rotavirus, vaccine
J. Equine Sci.

Vol. 16, No. 2

pp. 35-44, 2005
Equine rotavirus infection is a disease that causes acute diarrhea in foals [1]. The signs often observed in affected foals are diarrhea, pyrexia, depression and reluctance to suckle [10]. Depression and colic are often observed in serious field cases. The disease occurs in suckling foals, especially those less than 4 months old [6]. Usually fluids and antibiotics are given to foals with severe diarrhea to prevent severe dehydration, electrolyte imbalances and secondary bacterial infection. The disease is highly contagious, but the mortality rate is extremely low. The disease occures severely in newborn foals in the Hidaka region of Hokkaido, a major thoroughbred breeding district of Japan [6]. The serotypes and genotypes of

This article was accepted April 22, 2005

*Correspondence author. e-mail: imagawa@epizoo.equinst. go.jp rotaviruses are classified by differences in the antigenicity of two kinds of viral outer capsid protein (VP4 and VP7) or the VP4 coding gene. It has been confirmed that both the G3P [12] and G14P [12] rotaviruses spread in the Hidaka region of Hokkaido in 1996 and 1997 [14], although the G3P [12] rotavirus emerged between 1981 and 1991 [7, 11, 13]. It has been suggested that the G3P [12] rotavirus was predominant in surveys conducted on sera collected from yearlings in the same region in 1999, but the G14P [12] rotavirus has also spread [8]. In an epidemiological study of foal diarrhea conducted by the authors and others in the breeding region for 7 years, it was found that approximately $30 \%$ of foal diarrhea is caused by rotavirus infection [6]. Therefore, many breeders and veterinarians have voiced the need for the development of an effective equine rotavirus vaccine. In light of this history, we 
conducted a basic study of a prepartum equine rotavirus vaccine between 1994 and 1996 and proved by challenge test in experimental foals that the vaccine substantially reduced foal diarrhea caused by rotavirus infection, although it did not completely protect foals from diarrhea [5]. Powel et al. [12] conducted a field study with an inactivated equine rotavirus vaccine and suggested that vaccination of mares with equine rotavirus resulted in high colostral antibody concentrations, which in turn reduced the incidence of rotaviral diarrhea in their foals, compared with foals born to control mares. The objectives of our current study were to determine the safety and efficiency of an inactivated equine rotavirus vaccine in field trials.

\section{Materials and Methods}

\section{Vaccine}

Equine rotavirus HO-5 strain (G3P[12]) [7, 10] was used as the vaccine strain. Culture fluids of the virus $\left(10^{7.3} \mathrm{TCID}_{50} / 2 \mathrm{~m} l\right)$ were propagated on a monolayer of MA-104 cells by the methods described in a previous report [5]. The vaccine was prepared by inactivating the above viral culture fluids with $0.2 \%$ formalin for 24 $\mathrm{hr}$ at $37^{\circ} \mathrm{C}$ and subsequently adding aluminum phosphate at $2 \mathrm{mg} / \mathrm{m} l$ to serve as an adjuvant.

\section{Virus antigen detection and virus isolation from feces}

A latex agglutination test using Rota Screen (Microgen Bioproducts, England) was performed by the methods described in a previous report [4] to detect rotavirus antigen in feces. Virus was isolated from feces by the methods described in a previous report [9]. Isolated virus was identified as rotavirus by an indirect immunofluorescence technique with antiHO-5 antibody prepared in guinea pigs.

\section{Virus RNA detection in feces and VP7 typing by PCR}

Virus RNA was extracted from a $10 \%$ fecal suspension and culture fluid of isolated virus using an Isogen LS kit (Wako Pure Chemical Industries). First, the full-length VP 7 gene of rotavirus was amplified by PCR with the prime Beg9 (GGCTTTAAAAGAGAGAATTTCCGTCTGG) and End9 (GGTCACTCATACAATTCTAATCTAAG) and subsequently PCR was conducted with the G3 and G14 serotype-specific region as a primer. For G3 typing, the G3E primer (CAATCGAAGAGATTGCGACAG) was used, and for G14 typing, the G14D primer (GACGAAGCATTGCAATTA) was employed. PCR was conducted by the method described by Tsunemitsu $e t$ al. [14].

\section{Neutralization test}

A plaque-reduction neutralization test was conducted to measure antibody titers to the vaccine strain (HO-5) in the serum, colostrum and milk. The neutralization test was conducted as described by Hoshino et al. [3]. A serum neutralization test by virus dilution was also conducted to determine crossreactivity among the HO-5 strain, the FI-23 strain (G14P [12]) [2] and the isolated T-1 virus strain. The T-1 strain was representative of the rotaviruses isolated from foals with diarrhea on farm $T$. A serum neutralization test by virus dilution was performed in 48-well plastic dishes of MA-104 cell monolayers. Serum to be tested was used after heating at $56^{\circ} \mathrm{C}$ for 30 min. Each test serum was mixed with an equal volume of one of a number of serial ten-fold virus dilutions diluted with maintenance medium ( $\mathrm{pH} 7.6$ ) containing $0.295 \%$ tryptose phosphate broth (TPB) and $2 \mu \mathrm{g} / \mathrm{m} l$ crystal trypsin in Eagle's minimum essential medium (MEM). All mixtures were kept at $37^{\circ} \mathrm{C}$ for $1 \mathrm{hr}$. Then, $0.1 \mathrm{~m} l$ of mixture was inoculated into each of 4 wells with confluent monolayers of MA-104 cells that had previously been washed once with washing medium (pH7.4) containing $0.295 \%$ TPB in MEM. After adsorption at $37^{\circ} \mathrm{C}$ for $60 \mathrm{~min}$ in a $\mathrm{CO}_{2}$ incubator, the cultures were washed twice with washing medium. Maintenance medium at $0.5 \mathrm{~m} l$ was added to the each of the cultures, which were incubated at $37^{\circ} \mathrm{C}$ in a $\mathrm{CO}_{2}$ incubator. The cultures were then observed for the cytopathic effect (CPE) for 7 days. Serum-neutralizing activity was expressed as a neutralizing index indicating the difference in $\log$ virus titer between preimmunization sera and hyperimmune antisera.

\section{Hyperimmune antisera to equine rotavirus}

Hyperimmune antisera were prepared as follows. The two equine rotavirus reference strains (HO-5 and FI-23) and the isolate (T-1) were propagated in MA-104 cells and semipurified on sucrose gradients. Each $1 \mathrm{ml}$ of these antigens was mixed with an equal volume of Freund's complete adjuvant and inoculated into the muscles of guinea pigs twice, with a 1-month interval. Their sera were collected 1 week after the last inoculation. The pre-immunization serum of each guinea pig had a titer of less than $1: 4$ by neutralization 
testing.

\section{Field trial test}

Test term: The field study was conducted from 11 December 1998 to 25 July 1999.

Tested animals: The field study was conducted by using pregnant mares and their foals at two Thoroughbred breeding farms (farms $\mathrm{T}$ and $\mathrm{M}$ ) in Hokkaido. The horses tested on farm $\mathrm{T}$ consisted of 40 vaccinated mares, 40 foals born to these mares (vaccinated-group foals), 5 control mares and 5 foals born to these mares (control-group foals). The horses tested on farm M consisted of 20 vaccinated mares, 20 vaccinated-group foals, 4 control mares and 4 controlgroup foals. Vaccine was not given to the control mares.

Vaccination: A 2-ml dose was given twice with a 1month interval into the cervical muscles of each pregnant mare. The first vaccination was given at 8 or 9 months of gestation.

Clinical observation: The whole body and the inoculated area of each vaccinated pregnant mare were examined for adverse reactions for 2 weeks after vaccination. Delivery was also observed in the vaccinated mares. The foals were observed for growth and clinical signs for 3 months after birth.

Examination of foals with diarrhea: If foals developed diarrhea, virological tests, consisting of a latex agglutination test, PCR and virus isolation, were conducted on the feces to determine whether the diarrhea was caused by rotavirus or not. Moreover, the treatment given and progress of diarrhea in foals infected with rotavirus were investigated.

Determination of immunogenicity: The immunogenicity of the vaccine was evaluated by measuring the serum neutralizing ( $\mathrm{SN}$ ) antibody titers of mares and foals.

Sera were collected from all mares before first vaccination and at foaling and from all foals 3 days after birth. Enough colostrum was given to all foals. SN antibody titers of colostrum collected at foaling and of milk collected about 1 month after foaling were also measured.

Clinical signs and treatment of control-group foals infected with rotavirus that appeared on farm $\mathrm{T}$ in 1998: Inactivated equine rotavirus vaccine was not given to pregnant mares on farm $\mathrm{T}$ in 1998 or the previous year, when a field trial test was conducted. Therefore, foals born to these pregnant mares were used as control-group foals. A positive reaction of the latex agglutination test on loose feces confirmed that 30 of these control-group foals were infected with rotavirus. The clinical signs, treatment and duration of diarrhea observed in these infected foals were investigated from clinical records. To examine the effects of the vaccine, data on these infected foals were compared with the clinical signs, treatment and duration of diarrhea from rotavirus infection in vaccinated-group foals.

\section{Results}

\section{Safety}

Neither clinical signs of whole body illness, such as depression, anorexia and pyrexia, nor abnormalities at the injection site were observed in any of the 60 pregnant mares inoculated twice on farms $\mathrm{T}$ and $\mathrm{M}$. The deliveries of all vaccinated and control pregnant mares were normal, although a vaccinated mare on farm $\mathrm{T}$ leaked milk before delivery. During the 3 months after birth, no abnormalities in growth were observed in any of the foals in the vaccinated-and control-groups on farms $\mathrm{T}$ and $\mathrm{M}$.

Antibody response in vaccinated pregnant mares and immunity passively acquired through colostrum in foals

The SN antibody titers of the mares (serum, colostrum and milk) and foals (serum) on farm $\mathrm{T}$ are shown in Table 1. All vaccinated pregnant mares and control pregnant mares possessed neutralization antibodies pre-vaccination. At foaling, the serum titers of 36 pregnant mares vaccinated twice were 2- to 16-fold higher than those at pre-vaccination. The serum titers of the remaining 4 (T7, T22, T24 and T31) were the same at pre-vaccination and foaling. The serum titers of 4 of the control pregnant mares at pre-vaccination and foaling were the same, but in one control the titer at foaling was 2-fold lower than at pre-vaccination. The antibody response rate was $90 \%$ for vaccinated mares and $0 \%$ for control mares. At foaling, the serum titers of 37 of the vaccinated-group foals were either the same as their dams' or twice as high. The titers of the remaining three foals (T3, T5 and T11) were 2- to 4fold lower than those of mares at foaling. At foaling, the serum titers of 4 of the control foals were the same as their dams' at foaling or twice as high, and the titer of the remaining control foal was 2-fold lower than its dam's. 
Table 1. Neutralization antibody titers of mares and foal on farm $\mathrm{T}$

\begin{tabular}{|c|c|c|c|c|c|}
\hline \multirow{3}{*}{ No. } & \multicolumn{3}{|c|}{ Neutralization antibody titers of mares } & \multirow{3}{*}{ Milk } & \multirow{3}{*}{$\begin{array}{c}\frac{\text { Neutralization antibody titers of foals }}{\text { Serum }} \\
\text { 3 days after foaling }\end{array}$} \\
\hline & \multicolumn{2}{|c|}{ Serum } & \multirow[t]{2}{*}{ Colostrum } & & \\
\hline & Pre-vaccinatin & At foaling & & & \\
\hline $\mathrm{T}-1$ & 160 & 640 & 10,240 & 20 & 1,280 \\
\hline 2 & 640 & 1,280 & 10,240 & 20 & 1,280 \\
\hline 3 & 640 & 1,280 & 10,240 & 20 & 640 \\
\hline 4 & 320 & 2,560 & 20,480 & 80 & 2,560 \\
\hline 5 & 80 & 1,280 & 5,120 & 80 & 640 \\
\hline 6 & 80 & 320 & 1,280 & 10 & 320 \\
\hline 7 & 640 & 640 & 10,240 & 40 & 640 \\
\hline 8 & 320 & 1,280 & 10,240 & 40 & 2,560 \\
\hline 9 & 160 & 640 & 5,120 & 40 & 1,280 \\
\hline 10 & 80 & 320 & 1,280 & 20 & 320 \\
\hline 11 & 320 & 1,280 & 2,560 & 40 & 320 \\
\hline 12 & 1,280 & 2,560 & 20,480 & 40 & 2,560 \\
\hline 13 & 160 & 640 & 5,120 & 20 & 1,280 \\
\hline 14 & 640 & 1,280 & 10,240 & 80 & 2,560 \\
\hline 15 & 320 & 640 & 5,120 & 20 & 1,280 \\
\hline 16 & 320 & 640 & 20,480 & 40 & 640 \\
\hline 17 & 160 & 640 & 10,240 & 80 & 1,280 \\
\hline 18 & 1,280 & 2,560 & 40,960 & NT & 2,560 \\
\hline 19 & 320 & 640 & 20,480 & 40 & 1,280 \\
\hline 20 & 320 & 1,280 & 10,240 & NT & 2,560 \\
\hline 21 & 640 & 1,280 & 10,240 & 40 & 1,280 \\
\hline 22 & 640 & 640 & 10,240 & 40 & 1,280 \\
\hline 23 & 640 & 1,280 & 20,480 & 80 & 1,280 \\
\hline 24 & 640 & 640 & 10,240 & 20 & 640 \\
\hline 25 & 320 & 1,280 & 20,480 & 40 & 1,280 \\
\hline 26 & 640 & 2,560 & 20,480 & 80 & 2,560 \\
\hline 27 & 160 & 2,560 & 20,480 & NT & 5,120 \\
\hline 28 & 40 & 320 & 5,120 & NT & 640 \\
\hline 29 & 80 & 320 & 2,560 & 20 & 640 \\
\hline 30 & 320 & 1,280 & 20,480 & 80 & 1,280 \\
\hline 31 & 1,280 & 1,280 & 40,960 & 80 & 2,560 \\
\hline 32 & 640 & 1,280 & 40,960 & 80 & 2,560 \\
\hline 33 & 640 & 1,280 & 40,960 & 80 & 2,560 \\
\hline 34 & 160 & 640 & 5,120 & NT & 1,280 \\
\hline 35 & 640 & 2,560 & 40,960 & NT & 5,120 \\
\hline 36 & 640 & 1,280 & 20,480 & NT & 1,280 \\
\hline 37 & 2,560 & 5,120 & 40,960 & NT & 10,240 \\
\hline 38 & 2,560 & 5,120 & 40,960 & NT & 10,240 \\
\hline 39 & 640 & 2,560 & 40,960 & NT & 5,120 \\
\hline 40 & 640 & 1,280 & 40,960 & NT & 1,280 \\
\hline 41 & 640 & 320 & 5,120 & NT & 640 \\
\hline 42 & 640 & 640 & 10,240 & 40 & 1,280 \\
\hline 43 & 1,280 & 1,280 & 10,240 & 20 & 1,280 \\
\hline 44 & 2,560 & 2,560 & 5,120 & 80 & 1,280 \\
\hline 45 & 1,280 & 1,280 & 20,480 & 20 & 1,280 \\
\hline
\end{tabular}

T-1 40: Vaccinated group. T-4 45: Control group. NT: Not tested.

The geometric mean (GM) SN antibody titers of mares and foals on farm $\mathrm{T}$ are shown in Table 2 . In the 40 vaccinated pregnant mares, the GM serum titers at pre-vaccination and foaling were 1:375 and 1:1,094, respectively. The titer at foaling was 2.9-fold higher than at pre-vaccination. In contrast, in the 5 control mares, the GM serum titer at foaling (1:954) was lower than at pre-vaccination $(1: 1,094)$. The GM titers of 
Table 2. Geometric mean neutralization antibody titers of mares and foals tested on farm $\mathrm{T}$

\begin{tabular}{|c|c|c|c|c|c|c|}
\hline \multirow[t]{3}{*}{ Group } & \multirow{3}{*}{$\begin{array}{c}\text { No. of mares } \\
\text { tested }\end{array}$} & & & \multicolumn{3}{|c|}{ Neutralization antibody titer (GM) } \\
\hline & & \multicolumn{3}{|c|}{ Serum } & \multirow[t]{2}{*}{ Colostrum } & \multirow[t]{2}{*}{ Milk } \\
\hline & & Pre-vaccination & At foaling & Foals & & \\
\hline Vaccinated-group & 40 & 375 & 1,094 & 1,530 & 13,000 & 40.7 \\
\hline Control-group & 5 & 1,094 & 954 & 1,094 & 8,690 & 33.4 \\
\hline
\end{tabular}

Table 3. Neutralization antibody titers of mares and foals on farm $\mathrm{M}$

\begin{tabular}{|c|c|c|c|c|c|}
\hline \multirow[b]{3}{*}{ No. } & \multicolumn{3}{|c|}{ Neutralization antibody titers of mares } & \multicolumn{2}{|c|}{ Neutralization antibody titers of foals } \\
\hline & \multicolumn{2}{|c|}{ Serum } & \multirow[b]{2}{*}{ Colostrum } & \multirow[b]{2}{*}{ Milk } & \multirow{2}{*}{$\frac{\text { Serum }}{3 \text { days after foaling }}$} \\
\hline & Pre-vaccination & At foaling & & & \\
\hline M- 1 & 320 & 1,280 & 20,480 & 80 & 640 \\
\hline 2 & 1,280 & 2,560 & 40,960 & 20 & 5,120 \\
\hline 3 & 640 & 1,280 & 1,280 & 40 & 640 \\
\hline 4 & 160 & 2,560 & 20,480 & 160 & 5,120 \\
\hline 5 & 160 & 640 & 10,240 & 40 & 1,280 \\
\hline 6 & 640 & 2,560 & 20,480 & 40 & 2,560 \\
\hline 7 & 320 & 2,560 & 10,240 & 20 & 2,560 \\
\hline 8 & 640 & 2,560 & 20,480 & 160 & 5,120 \\
\hline 9 & 320 & 640 & 5,120 & 20 & 1,280 \\
\hline 10 & 160 & 640 & 10,240 & 40 & 2,560 \\
\hline 11 & 320 & 640 & 5,120 & 40 & 1,280 \\
\hline 12 & 160 & 640 & 5,120 & 80 & 1,280 \\
\hline 13 & 640 & 2,560 & 10,240 & 40 & 2,560 \\
\hline 14 & 320 & 640 & 5,120 & 40 & 1,280 \\
\hline 15 & 320 & 1,280 & 40,960 & 80 & 5,120 \\
\hline 16 & 80 & 1,280 & 10,240 & 80 & 1,280 \\
\hline 17 & 160 & 1,280 & 10,240 & 160 & 640 \\
\hline 18 & 640 & 2,560 & 10,240 & 160 & 2,560 \\
\hline 19 & 320 & 640 & 10,240 & 10 & 1,280 \\
\hline 20 & 160 & 1,280 & 10,240 & 80 & 1,280 \\
\hline 21 & 320 & 320 & 10,240 & 80 & 1,280 \\
\hline 22 & 1,280 & 1,280 & 10,240 & 20 & 80 \\
\hline 23 & 320 & 320 & 2,560 & 80 & 640 \\
\hline 24 & 1,280 & 1,280 & 5,120 & 80 & 1,280 \\
\hline
\end{tabular}

M-1-20: Vaccinated group. M-21-24: Control group.

colostrum were $1: 13,000$ in vaccinated mares and $1: 8,690$ in control mares. GM titers of milk were 1:40.7 for vaccinated mares and 1:33.4 for control mares. GM titers of foals were 1:1,530 for the 40 vaccinated-group foals ad 1:1,094 for the 5 control-group foals.

The SN antibody titers of mares (serum, colostrum and milk) and foals (serum) on farm $\mathrm{M}$ are shown in Table 3. All the vaccinated and control pregnant mares possessed neutralization antibodies at pre-vaccination. In the 20 pregnant mares vaccinated twice, serum titers at foaling were 2- to 8-fold higher than at prevaccination. The serum titers of 4 of the control pregnant mares at pre-vaccination and at foaling were the same. The antibody response rate was $100 \%$ for vaccinated mares and $0 \%$ for controls. The serum titers of 17 of the vaccinated-group foals ranged from values the same as those of their dams to 2- to 4-fold higher. On the other hand, the serum titers in the remaining three foals (M1, M3 and M17) were half those of their dams at foaling. The serum titers of three control foals at foaling ranged from values similar to those of their dams to twice as high, and the titer of the remaining foal was 16 -fold lower than that of its dam. The GM titers of mares and foals on farm $\mathrm{M}$ are shown in Table 
Table 4. Geometric mean neutralization antibody titers of mares and foals tested on farm M

\begin{tabular}{|c|c|c|c|c|c|c|}
\hline \multirow{3}{*}{ Group } & \multirow{3}{*}{$\begin{array}{l}\text { No. of mares } \\
\text { tested }\end{array}$} & \multicolumn{4}{|c|}{ Neutralization antibody titer (GM) } & \multirow{3}{*}{ Milk } \\
\hline & & \multicolumn{3}{|c|}{ Serum } & \multirow[t]{2}{*}{ Colostrum } & \\
\hline & & Pre-vaccination & At foaling & Foals & & \\
\hline Vaccinated-group & 20 & 298 & 1,280 & 1,775 & 10,320 & 52.3 \\
\hline Control-group & 4 & 640 & 640 & 529 & 5,940 & 56.2 \\
\hline
\end{tabular}

Table 5. Twenty three foals caused diarrhea in vaccinated group foals of farm $\mathrm{T}$ and virological tests using their diarrheal feces

\begin{tabular}{|c|c|c|c|c|c|c|c|c|}
\hline No. & Foal serum & Mare milk & $\begin{array}{l}\text { Grade of } \\
\text { diarrhea }\end{array}$ & $\begin{array}{l}\text { Age }^{1} \\
\text { (day) }\end{array}$ & $\begin{array}{l}\text { Diarrheal } \\
\text { term (days) }\end{array}$ & Latex & Isolation & PCR \\
\hline $\mathrm{T}-1$ & 1,280 & 20 & SS & $\mathrm{NC}$ & $\mathrm{NC}$ & - & NT & NT \\
\hline 2 & 1,280 & 20 & SS & $\mathrm{NC}$ & $\mathrm{NC}$ & + & NT & + \\
\hline 3 & 640 & 20 & SS & $\mathrm{NC}$ & $\mathrm{NC}$ & + & + & + \\
\hline 4 & 2,560 & 80 & SS & 66 & 3 & NT & NT & NT \\
\hline 5 & 640 & 80 & SS & 63 & 4 & + & NT & + \\
\hline 6 & 320 & 10 & WS & 74 & 8 & + & NT & + \\
\hline 8 & 2,560 & 40 & WS & 57 & 4 & + & + & + \\
\hline 9 & 1,280 & 40 & $\mathrm{~S}$ & 64 & 4 & + & + & + \\
\hline 10 & 320 & 20 & WS & 71 & 5 & + & + & + \\
\hline 11 & 320 & 40 & SS & $\mathrm{NC}$ & $\mathrm{NC}$ & + & + & + \\
\hline 12 & 2,560 & 40 & $\mathrm{~S}$ & 46 & 2 & - & NT & NT \\
\hline 14 & 2,560 & 80 & SS & 64 & 2 & - & NT & NT \\
\hline 17 & 1,280 & 80 & SS & 59 & 4 & + & NT & NT \\
\hline 19 & 1,280 & 40 & SS & $\mathrm{NC}$ & $\mathrm{NC}$ & - & - & - \\
\hline 23 & 1,280 & 80 & $\mathrm{~S}$ & 63 & 2 & + & + & + \\
\hline 25 & 1,280 & 40 & $\mathrm{M}$ & 70 & 3 & + & + & + \\
\hline 27 & 5,120 & NT & WS & 14 & 3 & + & + & NT \\
\hline 28 & 640 & NT & SS & $\mathrm{NC}$ & $\mathrm{NC}$ & + & - & + \\
\hline 32 & 2,560 & 80 & $\mathrm{~S}$ & $\mathrm{NC}$ & $\mathrm{NC}$ & - & NT & NT \\
\hline 34 & 1,280 & NT & M & 60 & 3 & + & NT & NT \\
\hline 38 & 10,240 & NT & SS & $\mathrm{NC}$ & $\mathrm{NC}$ & + & NT & NT \\
\hline 40 & 1,280 & NT & M & 62 & 3 & + & NT & NT \\
\hline 43 & 1,280 & 20 & SS & $\mathrm{NC}$ & $\mathrm{NC}$ & - & NT & NT \\
\hline
\end{tabular}

${ }^{1}$ Age developed diarrhea. T-1 to T-40: Vaccinated group. T-43: Control group. WS: Watery feces. M: Muddy feces. S: Soft feces. SS: Slight soft feces. NC: Not clear. NT: Not tested. +: Positive. -: Negative.

4. The GM titers of colostrum were 1:10,320 in vaccinated mares and 1:5,940 in control mares. In the 20 vaccinated pregnant mares, the GM serum titers at pre-vaccination and at foaling were 1:298 and 1:1,280, respectively: the titer at foaling was 4.3 -fold higher than at pre-vaccination. In contrast, for the 4 control mares, the GM serum titers at foaling and pre-vaccination were the same. GM titers of milk were 1:52.3 for vaccinated mares and 1:56.3 for control mares. GM serum titers of foals were $1: 1,775$ for the 20 in the vaccinated-group and 1:529 for the 4 controls.

\section{Occurrence of foal diarrhea on farms $T$ and $M$}

Twenty-two of the 40 vaccinated-group foals and one of the control-group foals on farm $\mathrm{T}$ foals had diarrhea, including soft feces. The diarrheal grade, age at development of diarrhea and duration of diarrhea in these 23 foals are shown in Table 5 . The diarrheal feces excreted by these foals were grouped into 4 grades. Of 22 vaccinated-group foals, 4 had watery feces, three muddy feces, three soft feces and 12 slightly soft feces. No diarrhea was observed in the 20 vaccinated-group foals and the 4 control-group foals on farm $\mathrm{M}$. 
Table 6. Clinical signs, age when developed diarrhea, duration of diarrhea and treatment of foals infected with rotavirus: vaccinated- and control-group foals

\begin{tabular}{|c|c|c|c|c|c|c|c|c|}
\hline \multirow[b]{2}{*}{ Group } & \multirow{2}{*}{$\begin{array}{l}\text { Number of foals } \\
\text { examined }\end{array}$} & \multicolumn{3}{|c|}{$\begin{array}{l}\text { Number of foals that showed } \\
\text { the following clinical signs }\end{array}$} & \multirow[b]{2}{*}{$\begin{array}{l}\text { Age developed } \\
\text { diarrhea }\end{array}$} & \multirow[b]{2}{*}{$\begin{array}{l}\text { Period of } \\
\text { diarrhea }\end{array}$} & \multicolumn{2}{|c|}{$\begin{array}{l}\text { Number of foals } \\
\text { given each treatment }\end{array}$} \\
\hline & & Diarrhea & Pyrexia & $\begin{array}{l}\text { Pyrexia } \\
\text { and } \\
\text { depression }\end{array}$ & & & $\begin{array}{l}\text { Infusion } \\
\text { and } \\
\text { antibiotic } \\
\text { medication }\end{array}$ & $\begin{array}{l}\text { Antibiotic } \\
\text { medication }\end{array}$ \\
\hline $\begin{array}{l}\text { Vaccinated- } \\
\text { group }\end{array}$ & $11^{1}$ & $11^{2}$ & 1 & 1 & $\begin{array}{l}14 \text { to } 74 \text { days } \\
\text { (Average } 60.0 \text { da }\end{array}$ & $\begin{array}{c}2 \text { to } 8 \text { days } \\
\text { Average } 3.9 \mathrm{~d}\end{array}$ & ys) & 11 \\
\hline $\begin{array}{l}\text { Control- } \\
\text { group }\end{array}$ & $30^{3}$ & $30^{4}$ & 0 & 30 & $\begin{array}{r}3 \text { to } 112 \text { days } \\
\text { (Average } 39.7 \text { da }\end{array}$ & $\begin{array}{l}5 \text { to } 21 \text { days } \\
\text { Average } 8.7 \mathrm{~d}\end{array}$ & ys) & 30 \\
\hline
\end{tabular}

${ }^{1}$ Foals T5, T6, T8, T9, T10, T17, T23, T25, T27, T34 and T40 (Table 7). ${ }^{2}$ Four foals excreted watery feces, three excreted muddy feces, and four excreted soft feces. ${ }^{3}$ Rotavirus infection confirmed by latex agglutination test of feces. ${ }^{4}$ Excreted watery feces.

Table 7. Cross-reactivity among isolated virus and two representative equine rotaviruses by neutralization test

\begin{tabular}{|c|c|c|c|}
\hline \multirow[b]{2}{*}{ Strain } & \multicolumn{3}{|c|}{$\begin{array}{l}\text { Remaining virus titers }\left(\log \operatorname{TCID}_{50} / \mathrm{m} l\right) \text { after } \\
\text { neutralization test of pre-immunization sera and hyperimmune } \\
\text { antisera to the three strains }\end{array}$} \\
\hline & Pre-immunization & HO-5 & FI23 \\
\hline $\begin{array}{c}\text { HO-5 } \\
(\mathrm{G} 3 \mathrm{P}[12])\end{array}$ & 6.50 & $3.75(2.75)^{1}$ & $4.00(2.50)$ \\
\hline $\begin{array}{c}\text { FI23 } \\
(\mathrm{G} 14 \mathrm{P}[12])\end{array}$ & 5.75 & $3.75(2.00)$ & $2.00(3.75)$ \\
\hline $\begin{array}{c}\mathrm{T}-1^{2} \\
(\mathrm{G} 14 \mathrm{P}[12])\end{array}$ & 7.00 & $4.25(2.75)$ & $2.50(4.50)$ \\
\hline
\end{tabular}

${ }^{1}$ Parenthesis shows numerical value which the virus $\log$ titer shown by the reaction of hyperimmune antiserum and virus strain was subtracted from the virus $\log$ titer shown by the reaction of preimmunization serum and virus strain. ${ }^{2}$ Isolated virus.

Virological tests for rotavirus in diarrheal feces from farm $T$

The results of virological testing for rotavirus in the feces of the 23 foals with diarrhea on farm $\mathrm{T}$ are shown in Table 5. Sixteen of 22 fecal samples tested by latex agglutination, 8 of 10 tested for virus isolation and 11 of 12 feces tested by PCR were positive for rotavirus. All genes detected in the 11 PCR-positive samples corresponded to those of the rotavirus G14 serotype.

Comparison of clinical signs and treatments in vaccinatedand control-group foals infected with rotavirus

The clinical signs, treatment, age at development of diarrhea and duration of diarrhea in 11 vaccinatedgroup foals infected with rotavirus in 1999 and 30 control-group foals infected with rotavirus in 1998 are shown in Table 6 . Of the 11 vaccinated-group foals, 4 excreted watery feces, three excreted muddy feces and 4 excreted soft feces. One of the 11 also had pyrexia and another had pyrexia and depression. The average age at which these 11 foals developed diarrhea was 60 days and the average duration of the diarrhea was 3.9 days. In contrast, all 30 control-group foals excreted watery feces and had pyrexia and depression. The average age at which these 30 foals developed diarrhea was 39.7 days and the average duration of diarrhea was 8.7 days.

Cross-reactivity among the isolated T-1 strain virus and the two representative equine rotavirus strains, G3P [12] and G14P [12]

The cross-reactivity among the isolated virus $\mathrm{T}-1$ strain, the HO-5 strain (G3P[12] ) and the FI23 strain 
(G14P[12]), as determined by neutralizing tests, is shown in Table 7. Although the T-1 strain cross-reacted with immune sera to both the HO-5 and FI23 strains, it cross-reacted more closely with the immune serum to FI23 than with that to HO-5. The HO-5 and FI23 strains also cross-reacted with each other, but at a lower level than that of a homologous reaction.

\section{Discussion}

We have already reported the immunogenicity and efficiency of the equine rotavirus vaccine in diarrhea prevention [5]. In our previous study, we found that pregnant mares vaccinated twice acquired 2- to 256-fold higher ELISA antibody titers compared with prevaccination. Foals that acquired ELISA antibody titers of more than 1:1,280 from parental colostrum were protected from diarrhea caused by homologous rotavirus infection; even if they developed diarrhea, it was slight. Our field study of inactivated equine rotavirus vaccine was conducted on the strength of these previous results.

No abnormal signs were observed in the whole body or at the injection site in a total of 60 pregnant mares vaccinated twice on the two farms tested. All the deliveries of the vaccinated pregnant mares were normal and their foals were born normally. The growth of all foals was also normal. Although one of the vaccinated mares leaked milk before delivery, this was not considered to be related to the vaccination. From these results, we confirmed that the vaccine was safe for pregnant mares and their foals.

In our previous report, we suggested that two doses of vaccine were needed to give pregnant mares high levels of antibody [5]. Two doses were also given to pregnant mares in the field trials, in conformity with our previous results. A rise of $\mathrm{SN}$ antibody titer was observed in 56 of the 60 pregnant mares $(93.3 \%)$ vaccinated twice on farms $\mathrm{T}$ and $\mathrm{M}$. The remaining 4 mares, in which antibody did not rise after vaccination, possessed SN antibody titers of 1:640 and 1:1,280 prevaccination. This suggested that vaccine break may occur in pregnant mares that have comparatively high SN antibody titers pre-vaccination. The GM SN antibody titer of the 40 pregnant mares at foaling on farm $\mathrm{T}$ was 2.9-fold higher than pre-vaccination and the GM SN antibody titer of the 20 pregnant mares at foaling on farm $M$ was 4.3-fold higher than prevaccination. From these results, we confirmed that the vaccine possessed effective immunogenicity in the pregnant mares.

We previously reported that foals acquired almost the same ELISA antibody titers as those of their dams through colostrum [5]. In our present field test, almost all the foals that drank colostrum possessed SN titers similar to, or slightly higher than, those of their dams. All 60 vaccinated-group foals on farms $T$ and $M$ possessed SN antibody titers between 1:320 and $1: 10,240$, and the GM SN antibody titers of the foals on both farms were $1: 1,530$ and 1:1,775, respectively. We showed in our previous paper [5] that foals that acquired ELISA antibody titers of more than 1:1,280 were effectively protected from diarrhea caused by rotavirus infection, although this protection was not complete. All antibody titers were shown as SN antibody titers in this study. To appraise the results of the previous study it was important to determine the SN antibody titer that would prevent diarrhea from rotavirus infection in foals. For the reason, we newly conducted SN tests on the foal sera used for the challenge tests in our previous paper [5]. The results showed that diarrhea could be prevented or minimized in the face of homologous rotavirus challenge if foals possessed SN antibody titers of at least 1:320 [our unpublished data]. We also found in the present field study that foals acquired effective antibodies against rotavirus infection through colostrum from their vaccinated dams.

Twenty-two of the 40 vaccinated-group foals on farm $\mathrm{T}$ had diarrhea. Three kinds of rotavirus-detecting tests were conducted to examine whether rotavirus was present in their feces. Sixteen fecal samples were positive on the latex agglutination test, 8 on virus isolation and 11 on PCR for rotavirus. Only the G14 serotype rotavirus gene was detected in all 11 PCRpositive fecal samples. These results suggested that 16 foals on farm $\mathrm{T}$ might have developed diarrhea by infection with the G14 serotype rotavirus, which was different from the G3 serotype vaccine strain. It was not concerned with rotavirus infection, although one of the 5 control group foals had diarrhea.

As the control group foals on farm $\mathrm{T}$ were not infected with rotavirus in 1999, we could not examine the diarrhea-prevention effect of the rotavirus vaccine in vaccinated- and control-group foals in that year. However, diarrhea caused by rotavirus occurred frequently among control-group foals on farm $\mathrm{T}$ in 1998. We were thus able to compare the clinical signs and treatment of the control-group foals in 1998 and 
vaccinated-group foals in 1999, infected with rotavirus on farm $T$. The grade of diarrhea observed in vaccinated-group foals was distinctly milder than that in control-group foals. Moreover, pyrexia and anorexia were observed in all of the control group foals but was rare in the vaccinated-group foals. The diarrhea in the control-group foals was very severe and these foals required fluids to prevent dehydration. In contrast, the diarrhea in the vaccinated- group foals was mild and they did not need fluids. Moreover, the duration of the diarrhea in the vaccinated-group foals was approximately half the number of days in the controlgroup. The grade of diarrhea in the vaccinated group foals was distinctly milder than that in the controls. Although the $G$ serotype that infected the vaccinatedgroup foals on farm $\mathrm{T}$ was the G14 serotype, which was different from the G3 vaccine strain, the clinical signs in this group were comparatively mild. This suggests that the vaccine prepared from G3 rotavirus can reduce the signs of diarrhea caused by G14 serotype rotavirus infection. Rotavirus infection of control-group foals was proved by the latex agglutination test. Accordingly, we did not know the serotype of rotavirus that infected these foals. However, it is considered generally that there is no difference in the pathogenesis of G3 and G14 rotavirus infections in foals. Therefore, we considered it acceptable to use the control-group foals as controls for the vaccinated-group.

G3 and G14 serotype rotavirus share the P[12] genotype, which codes another neutralizing viral surface protein. Therefore, it is known that these rotaviruses partly cross-react with each other $[2,8]$. In our study, also, the T-1 isolated strain (G14 serotype) cross-reacted with the HO-5 strain (G3 serotype) used as the vaccine strain.

One reason why the diarrhea in the vaccinated group of foals on farm $\mathrm{T}$ was comparatively mild might have been cross-reaction of the isolated virus with the vaccine strain. On the other hand, 16 (40\%) of 40 foals in the vaccinated group had diarrhea due to rotavirus infection. An important determinant of which foals developed diarrhea might have been that the foals were infected with the G14 serotype rotavirus, which was different from the vaccine strain.

All of these results indicated that the vaccine was safe for pregnant mares and foals and could distinctly reduce the signs of diarrhea and pyrexia caused by rotavirus infection.

\section{Acknowledgments}

We thank Dr. S. Ueda, Chairman of the Board of Directors of the Nippon Institute for Biological Science, for recognizing the need to conduct studies aimed at developing an inactivated equine rotavirus vaccine and for kindly offering us his advice and guidance. We are also indebted to Dr. T. Matsumura of the Epizootic Research Center for his advice in drawing up the manuscript.

\section{References}

1. Browning, G.F. 1996. Equine rotavirus infections. pp.127-135. In: Virus infections of equines. (Studdert, M.J. ed.), Elsevier, Amsterdam, Lausanne, New York, Oxford, Shannon, Tokyo.

2. Browning, G.F., Fitzgerald, T.A., Chalmers, R.M. and Snodgrass, D.R. 1991. A novel group A rotavirus $\mathrm{G}$ serotype: serological and genomic characterization of equine isolate FI23. J. Clin. Microbiol. 29: 2043-2046.

3. Hoshino, Y., Wyatt, R.G., Greenberg, H.B., Flores, J., and Kapikian, A.Z. 1984. Serotypic similarity and diversity of rotaviruses of mammalian and avian origin as studied by plaque-reduction neutralization. J. Infec. Dis. 49: 694-702.

4. Imagawa, H., Fukunaga, Y., Kanemaru, T., and Kamada, M. 1989. Detection of equine rotavirus in feces by latex agglutination. Bull. Equine Res. Inst. 26: $47-52$.

5. Imagawa, H., Fukunaga, Y., and Wada, R. 1998. Passive immunity in Foals of mares immuninised with inactivated equine rotavirus vaccine. pp. 201205. Proc. 8th Int. Conf. Equine Inf. Dis. (Wernery, U., Wade, J.F, Mumford, J.A. and Kaaden, O-R. eds), R \& W Publications (Newmarket.).

6. Imagawa, H., Sekiguchi, K., Anzai, T., Fukunaga, Y., Kanemaru, T., Ohishi, H., Higuchi, T., and M. Kamada. 1991. Epidemiology of equine rotavirus infection among foals in the breeding region. $J$. Vet. Med. Sci. 53: 1079-1080.

7. Imagawa, H., Tanaka, T., Sekiguchi, K., Fukunaga, Y., Anzai, T., Minamoto, N., and M. Kamada. 1993. Electropherotypes, serotypes and subgroups of Equine rotaviruses isolated in Japan. Arch. Virol. 131: 169-176.

8. Imagawa, H., Tsunemitsu, H., Wada, R., and Fukunaga, Y. 2002. Sero-epidemiological survey of equine rotavirus infections in 1-year-old 
thoroughbred horses in the Hidaka region of Hokkaido. J. Equine Sci. 13: 71-74.

9. Imagawa, H., Wada, R., Hirasawa, K., Akiyama, Y., and T. Oda. 1984. Isolation of equine rotavirus in cell cultures from foals with diarrhea. Jpn J. Vet. Sci. 46: 1-9.

10. Imagawa, H., Wada, R., Kamada, M., Kumanomido, T., Fukunaga, Y., and Hirasawa, K. 1984. Experimental infection of equine rotavirus in foals. Bull. Equine Res. Inst. 21: 65-71.

11. Ohta, C., Hoshi, A., Goto, H., Tsunoda. N., Tagami, M., and Akita, H. 1990. Epizootiological and virological studies of foal diarrhea associated with serotype 3 rotavirus. Jpn. J. Vet. Sci. 52: 10491056.

12. Powell, D.G., Dwyer, R.M., Traub-Dargatz, J.L.,
Fulker, R.H., Whalen, J.W. Jr., Srinivasappa, J., Acree, W.M., and H.J. Chu. 1997. Field study of the safety, immunogenicity and efficacy of an inactivated equine rotavirus vaccine. Am. Vet. Med. Assoc. 211: 193-198.

13. Takagi, M., Taniguchi, K., Urasawa, T., Urasawa, S., Shirahata, T., and Goto, H. 1994. Characterization of a G14 equine rotavirus (strain CH3) isolated in Japan. Arch Virol. 139: 209-215.

14. Tsunemitsu, H., Imagawa, H. , Togo, M., Shouji, T., Kawashima, K., Horino, R., Imai, K., Nishimori, T., Takagi, M., and T. Higuchi. 2001. Predominance of G3B and G14 equine group A rotaviruses of a single VP4 serotype in Japan. Arch. Virol. 146: 1949-1962. 